\title{
Implementation-based design - upfront thinking for tailings, soft soil, sediment and fly ash projects
}

\author{
K Fabian USA
}

\begin{abstract}
This treatise proposes an approach to mine tailings projects based on the overall comprehension of the civil-geotechnical requirements of the project. It also considers the management of mine waste and how the project fits into the surrounding environment taking into consideration the neighbourhood, public, impact on traffic, noise, odour, lighting and other potential impacts, and environmental constraints.
\end{abstract}

Keywords: soft soil, sediment, tailings, fly ash remediation

\section{Introduction}

The usual process of mining engineering project execution is investigation, site evaluation, pre-feasibility design, design, bidding, construction and reporting. This treatise offers an organic approach involving understanding the owner's ultimate goals, and from day one to understand project constraints and opportunities, and develop a broad approach to total project execution.

In mining projects, one of the largest implementation challenges is the availability of water to use for ore treatment and the movement of mine waste. Impacts to surface water and groundwater are of crucial importance and need to be understood from very early on, and the evaluation and selection of suitable technologies to optimise the use of the efficient delivery of soft soil, sediment and tailings is of great importance.

\section{Implementation-based design}

The mining consultant needs to focus on the implementability of options. This will drive the feasibility evaluation and design, allowing for the assessment of options and cost control for the owner and the negotiating capability with regulators and agencies whilst developing a relationship with the community, with due attention to environmental and resource constraints and opportunities. Implementation-based design focuses on the end goal of the project, what the owner wants to achieve, and it peels back to the steps considering what construction methods can be reasonably employed, what design these methods require, and what investigation the design requires. Sometimes this is called reversed engineering. In addition, implementation-based design considers various project constraints such as the environment and the implementation of projects in human surroundings. Therefore, utmost consideration must be paid to potential impacts on the human surroundings, such as noise, odour, nuisance, and the impact on traffic during project implementation. Environmental conditions such as fish movement patterns, migratory bird paths, nesting seasons, and the potential emissions, releases and leakages must also be considered.

Implementation-based design must be able to consider and incorporate available assets, such as unused impoundments, tanks, buildings, equipment, labour resources, and even the possibility of combining waste streams to generate a chemically neutral backfill. The mantra is 'use what you have to the benefit of all'.

Implementation-based design also includes the extensive involvement of the owner, regulators, and other stakeholders. Understanding the regulatory environment, public sentiment and the owner's needs and preferences and combining these into a comprehensive engineering approach, together with the civil/geotechnical/mining considerations (comprehensively known as geoenvironmental engineering considerations) is the overall goal of the approach (Fabian 2016). 


\subsection{Kettle River upstream expansion of tailings dam}

In this project, the owner (Echo Bay Minerals, later Kinross) was interested in expanding the volume of the tailings dam at their mine tailings facility at Republic, Washington, USA while the allowed footprint was exhausted. Therefore, an upstream expansion was the only plausible solution. The design process involved:

- Extensive evaluation of tailings strength to facilitate upstream construction.

- Seismic evaluation.

- Evaluation of how to convert a downstream double liner into an upstream double liner (first in the world).

- Construction quality control for a double liner installation.

- Construction quality control including proper timing for the placement of the upstream fill to avoid overloading of the tailings.

Construction permit approval was obtained from the Washington State Department of Ecology and the project was completed in 2001. A paper by Fabian et al. (2002) provides additional details on the design and construction.

The project is considered a success for implementation-based design, because the end goal was conceived early on, the technical issues were resolved, construction method and timing was developed, and the appropriate quality management system to verify the construction to the regulators and the owner was set out. Figure 1 shows the upstream lift of the dam.

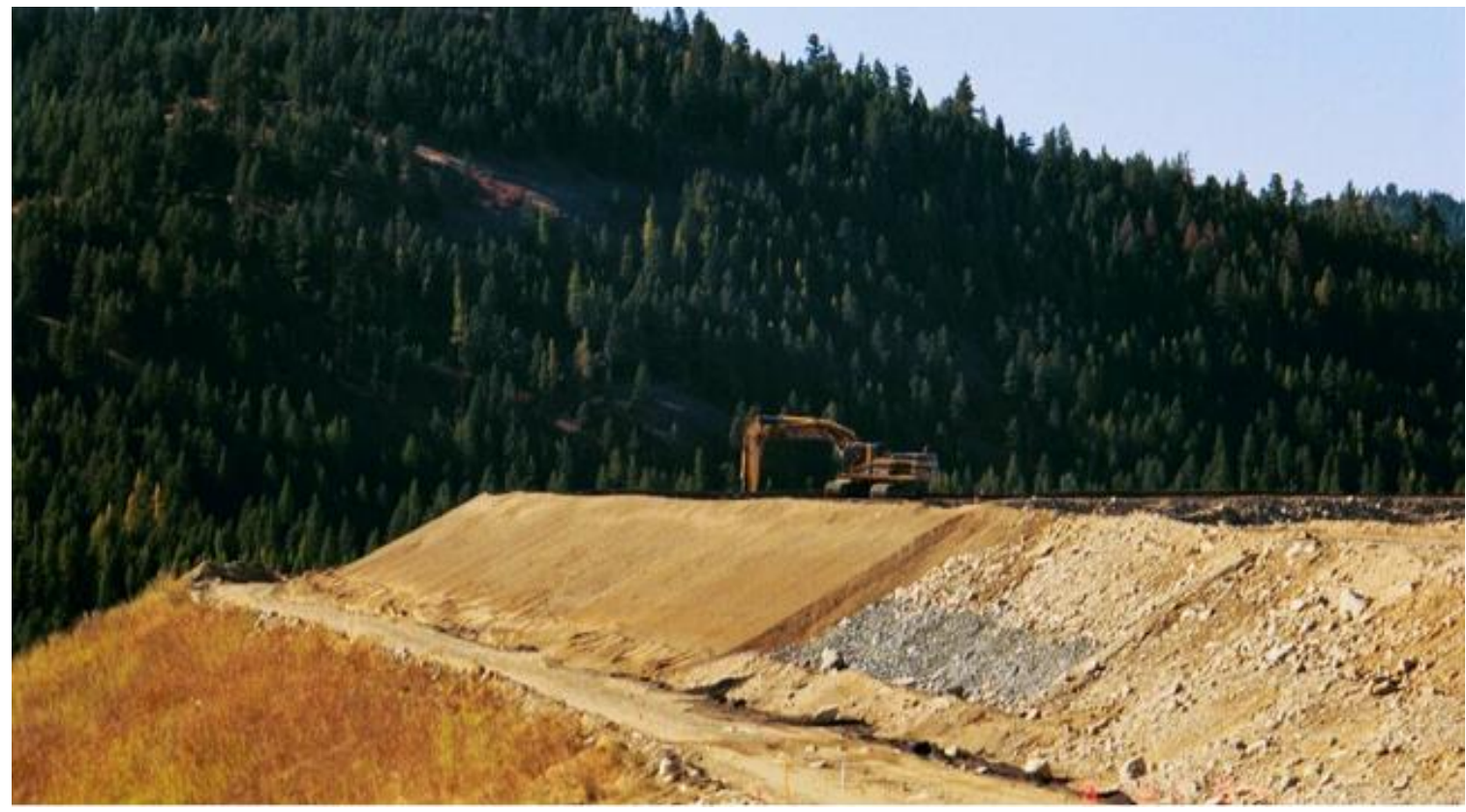

Figure 1 Upstream lift on the Kettle River tailings dam

\subsection{Richmond Refinery - No. 1 Oxidation Pond closure}

The refinery established in the early 1900s developed treatment towers, tanks and other refinery facilities. During the annual so-called 'turnaround' these facilities were cleaned with sand and water and the resulting sludge, about $1 \mathrm{M}$ per calendar year, was placed in the No. 1 Oxidation Pond (70 acres). One portion of the pond (Pass 1) was later turned into a water treatment facility. In addition, the refinery had about 11 hectares of mercury contaminated sediment (about 100,000 tonnes) in the San Pablo Bay, adjacent to the oxidation 
pond, and about 300,000 tonnes of 'potentially total petroleum hydrocarbon (TPH) impacted soil', not necessarily contaminated, but by rule (coming from a refinery) considered impacted.

The refinery is in Richmond, in a highly populated area, and any roads to a landfill would lead through highly populated areas of about two million people. The general approach was to minimise the potential impact to the community. Therefore the mantra was employed that 'everything stays onsite' - no trafficking through highly populated areas. This is safest for the surrounding community, and keeps any environmental liability onsite and under the owner's control. It also eliminates any commingling with someone else's waste in a landfill possibly leading to lengthy arguments and litigation, and managing all liability for perpetuity onsite. Accordingly, the following process was established:

- Dredge $100,000 \mathrm{~m}^{3}$ mercury impacted sediment using a high solid content dredging/pumping technology and place it on top of the oily sediment.

- Also place about 300,000 tonnes of potentially TPH impacted soil over No. 1 Oxidation Pond.

- Stabilise the top $6 \mathrm{ft}(2 \mathrm{~m})$ of the surface of the oxidation pond including the mercury impacted sediment and the impacted soil.

- Place crushed rock/gravel to serve as a final surface suitable for storage, parking and staging for construction projects.

Figure 2 shows the site at 2003 in its original pre-treatment condition. Figure 3 shows the site after remediation, having it converted into closed, paved land.

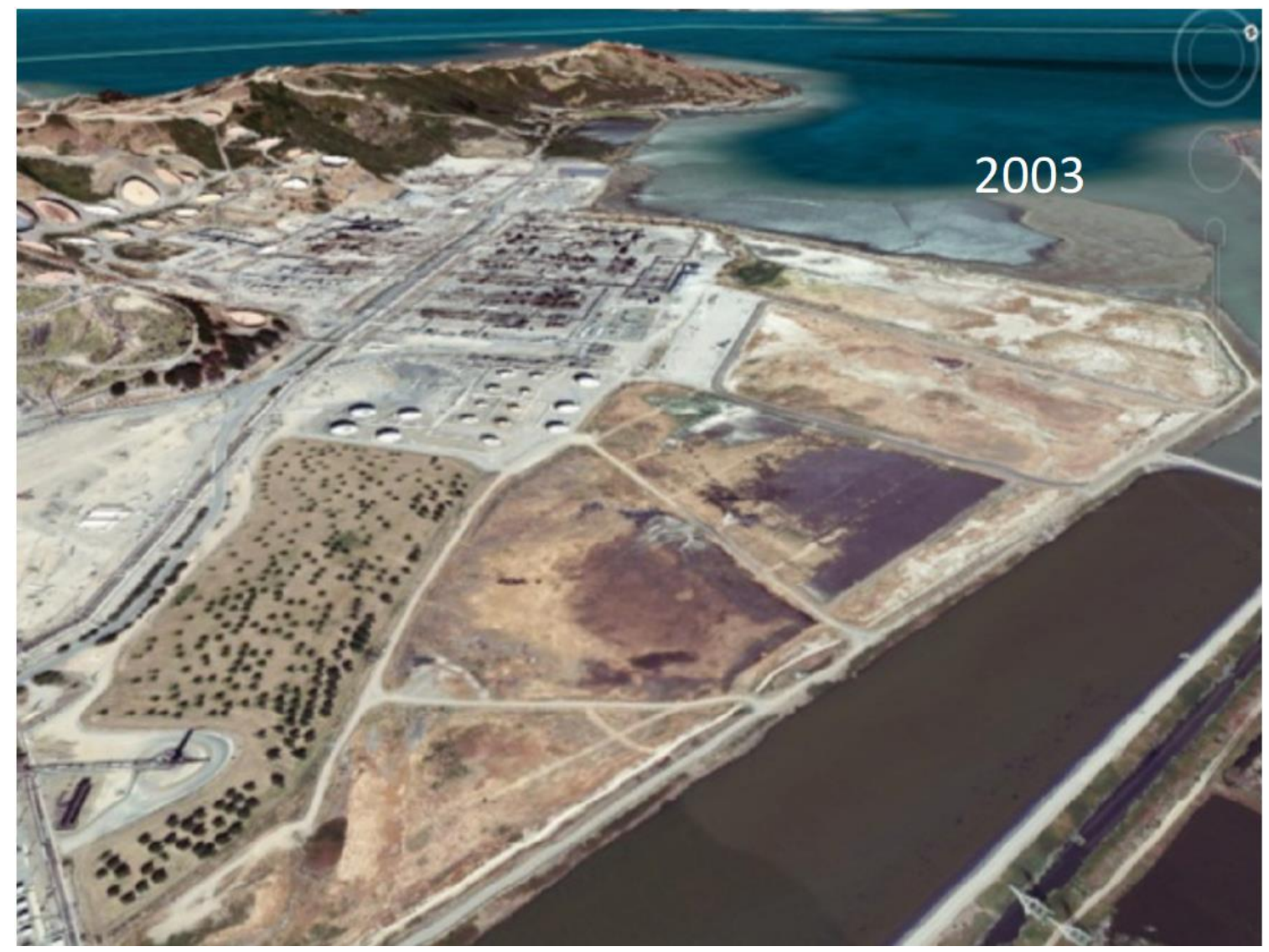

Figure 2 Aerial photo of the oxidation pond from 2003 




Figure 3 Photo of the oxidation pond after the reclamation was completed in 2011

The site remediation also included the creation of a road across the pond to assist the access of emergency vehicles to the refinery. Based on the expected vehicle load the thickness of the stabilised material was increased to $2.5 \mathrm{~m}$ along the alignment of the emergency road.

As a final note, the ongoing quality control and acceptance of the stabilisation was performed on a real-time basis using dynamic cone penetrometer testing, providing very fast feedback on the success of the construction and allowing adjustments to the mixing on a real-time basis.

The work was done between 2006 and 2011 and site closure from the Regional Water Quality Board was obtained in 2012, extinguishing all environmental liability and allowing the use of the closed No. 1 Oxidation Pond for refinery purposes. This essentially gave 66 acres of waterfront land to the refinery, greatly increasing its real estate value and operational flexibility. Several papers (Schifano et al. 2010; Fabian et al. 2010; Schifano \& Fabian 2010) provide more details on the laboratory evaluation, test pad construction and the details of the execution of the project. The project included the beneficial re-use of the pond, minimising environmental liability without any impact on the community.

\subsection{Farley Mine closure}

The Farley Mine was one of the largest mines in the nickel belt in Manitoba, Lynn Lake. The mine closure (one of the largest in the world on 400 hectares) was performed between 2008 and 2012 by closing the waste mine parcels (West Tailings Management Area) and the tailings ponds (East Tailings Management Area), including the creation of a water treatment plant and the management of the open pit containing acidic leftover mine water.

The closure involved the evaluation of the waste rock and tailings areas, including the containment berms under Canadian Dam Association (CDA) rules. Approximately $1.5 \mathrm{~km}$ of containment berms were re-structured to meet CDA requirements.

An area of approximately 40 hectares was closed using a geosynthetic clay liner (GCL) closure cap. The rest of the tailings area was extensively investigated for infiltration and acid generation. It was decided that 
grading on the relatively fine and therefore inherently low permeability tailings will require only grading and surface compaction, and will serve as its own low permeability cover reducing the potential of acid generation. A water treatment plant was also installed using lime treatment of acidic tailings liquids, with deliberate overdosage of lime, and the resulting still alkaline sludge was used to treat the standing water in the former mine pit (Kilkenny et al. 2011).

Figure 4 shows the mine site prior to remediation, and Figure 5 shows the completed closure of the tailings pond.

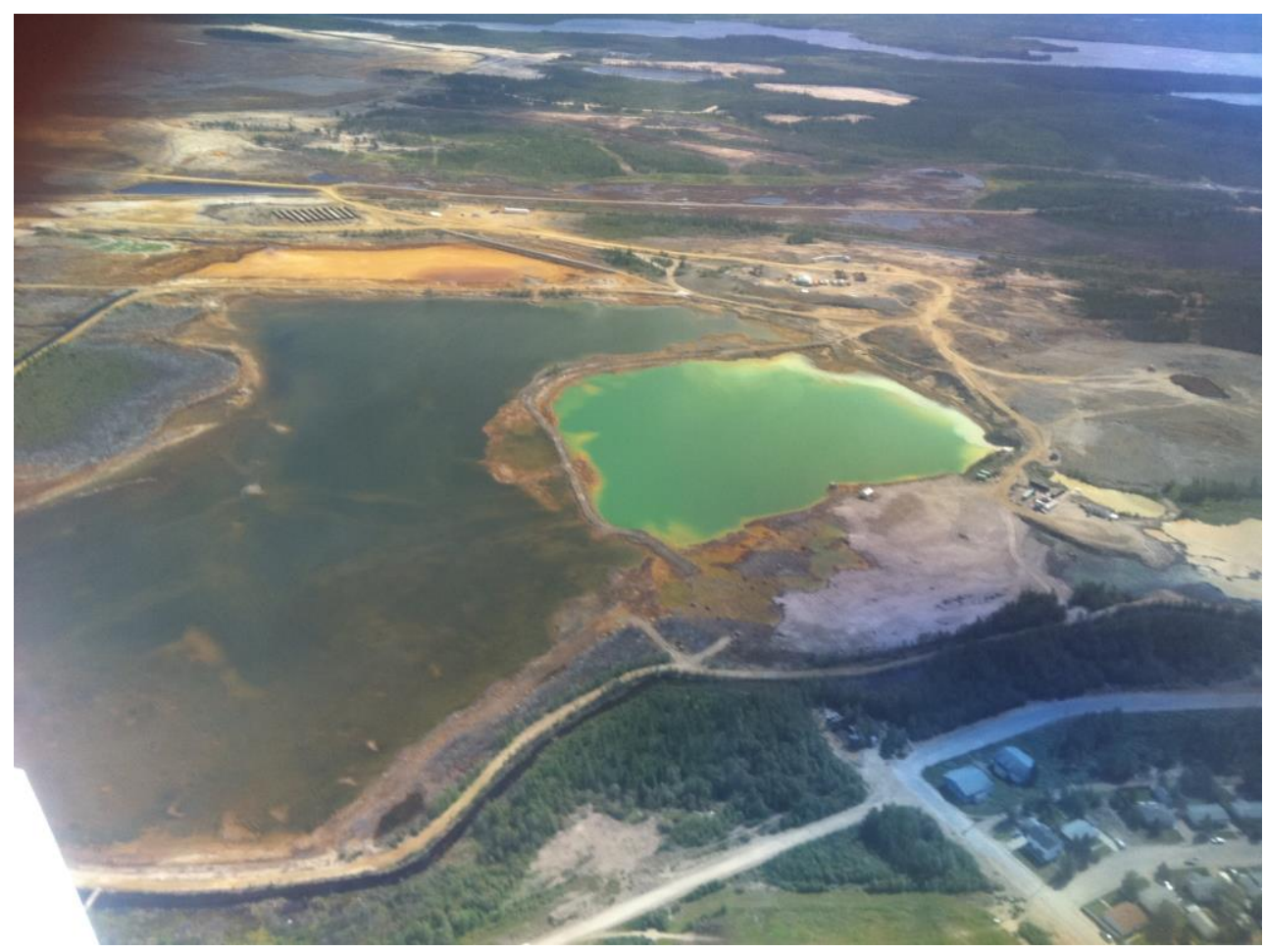

Figure 4 Farley Mine pit and tailings area before remediation

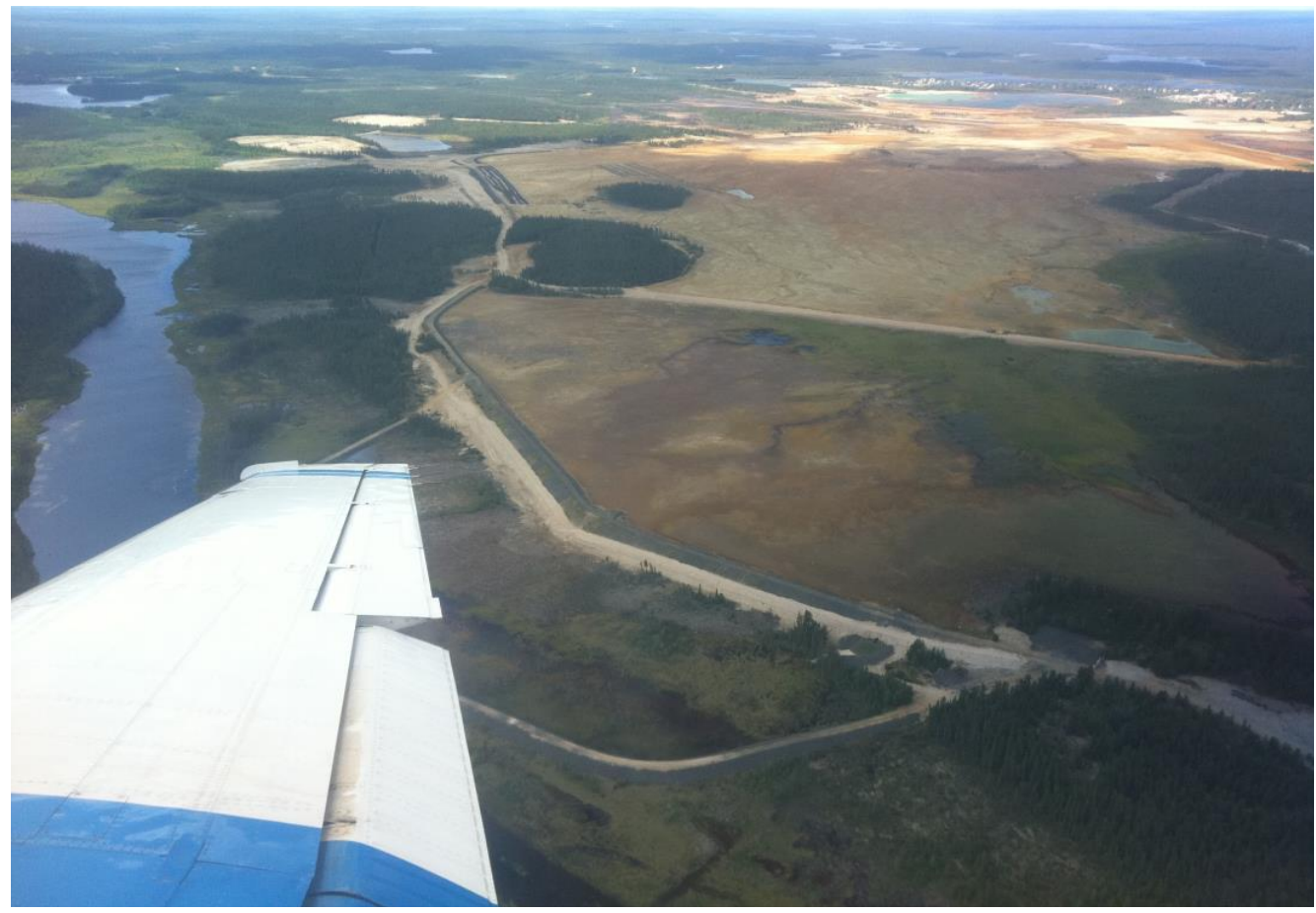

Figure 5 Farley Mine after the successful closure of the tailings pond 
At the Farley Mine the implementation-based design concept was utilised by understanding and properly considering local conditions such as the constraints of logistics, climate, geotechnical conditions, and the proximity of the City of Lynn Lake and other valuable surface water resources. Opportunities such as the availability of land, materials, and local labour, as well the use of lime-rich water plant effluent for open pit mine treatment were also considered.

\subsection{Visonta fly ash pond closure}

The Visonta power plant has been in operation since the early 1940s, using locally available lignite. The mine operation uses strip mine technology and recently has been importing more lignite from nearby sources. The power plant generates a significant amount of fly ash and a technique was developed to convert the fly ash into stable, useable land. The fly ash has been stabilised using cement and the resulting paste/slurry, referred to as dense slurry, is being pumped into storage ponds. This is an effective use of paste technology to generate a relatively stable surface almost immediately after pumping (Figure 6). The paste (dense slurry) then turns into pyramids of stabilised fly ash and is cultivated for agricultural purposes, such as in Figure 7 as an acacia forest producing huge volumes of honey.

Figure 6 shows the stabilised fly ash pumped into the pond and Figure 7 shows the completed pyramid with the forest as well as utilising the top of the hill for a solar power plant. The dense slurry system is a highly effective paste technology specifically developed for the coal power plants, where a large amount of fly ash is generated and handled. This technology is now considered for numerous power plants in the USA and elsewhere in the world, and its main element, the mixing of various reacting materials, was also utilised in the previously presented project, Richmond Refinery No. 1 Oxidation Pond.

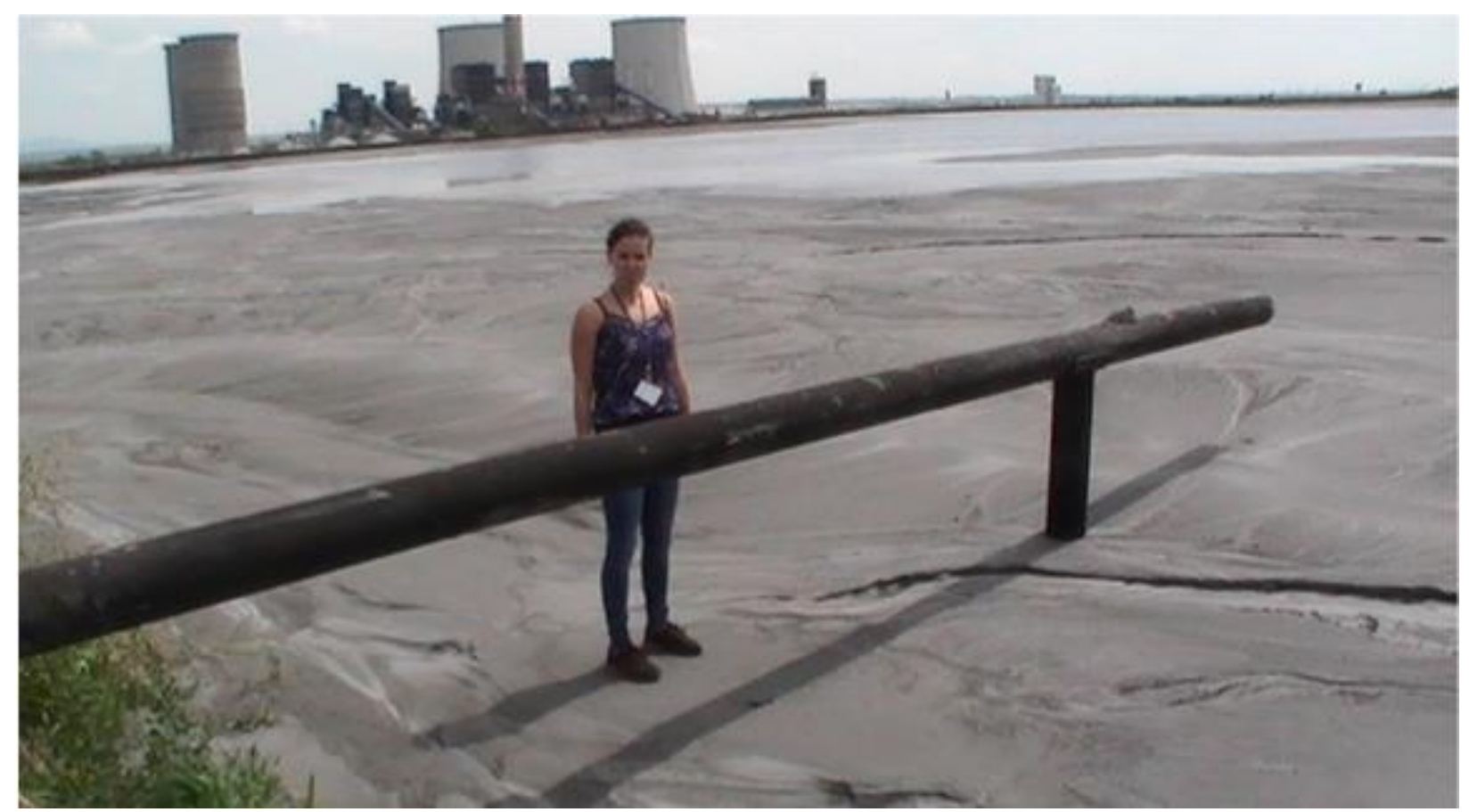

Figure 6 Cement stabilised fly ash paste shortly after discharge (photo courtesy AECOM and ENEXIO) 


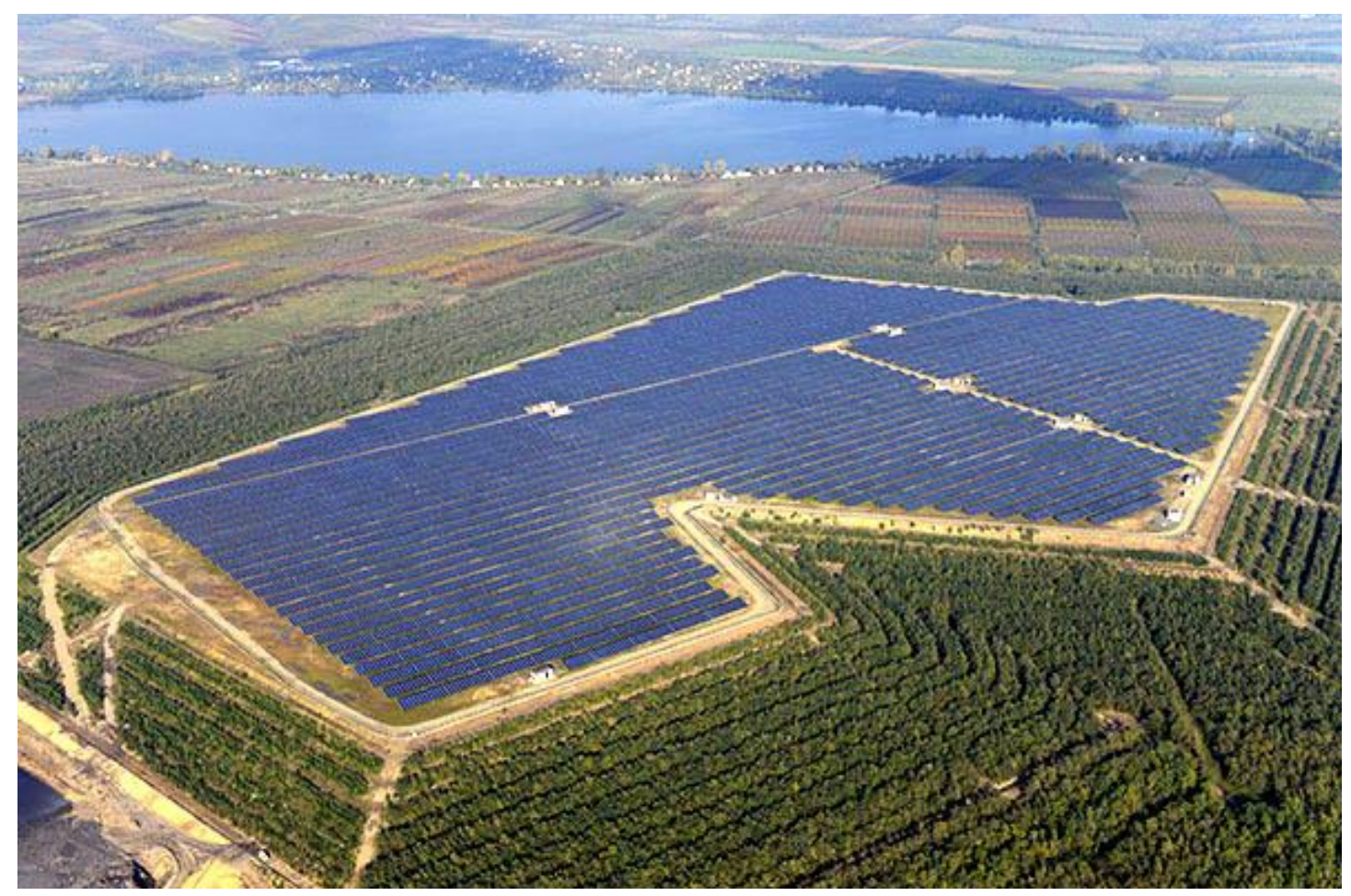

Figure 7 Stabilised fly ash paste pyramid serving as an acacia orchard and solar power plant (photo courtesy ENEXIO)

\subsection{Minera Penasquito tailings pond expansion and water management}

This project, presented at the 18th International Seminar on Paste and Thickened Tailings (Fabian et al. 2015), demonstrates the value of water for mining operations. Without water mines cannot operate, treat metals or move mine waste. The implementation-based design on this project was established to understand the climatic conditions in the high desert in Mexico and to understand the water needs of this mine and geological and engineering conditions affecting the operation.

The general idea of the expansion of the tailings dam was to use thickened tailings, instead of the cyclones, which were used up to 2015. Extensive testing was performed on tailings samples and the results indicated that the practice of thickening greatly reduces the water usage in the tailings getting to an approximately $60 \%$ solids content tailings, at an average settled density of $1.37 \mathrm{t} / \mathrm{m}^{3}$. Figure 8 shows the aerial view of the tailings dam in 2014.

This also allowed the use of centreline construction using primarily waste rock for the dam wall, only slightly increasing the footprint and minimising waste disposal. The project also included the evaluation of three other tailings pond locations around the mine to further possible mine expansion and through that increasing the economic value and occupational opportunities to the Penasquito area, in Zacatecas, Mexico. The project was a success on all fronts, including the owner and the community, bringing more work to the area, and to the local economy. 


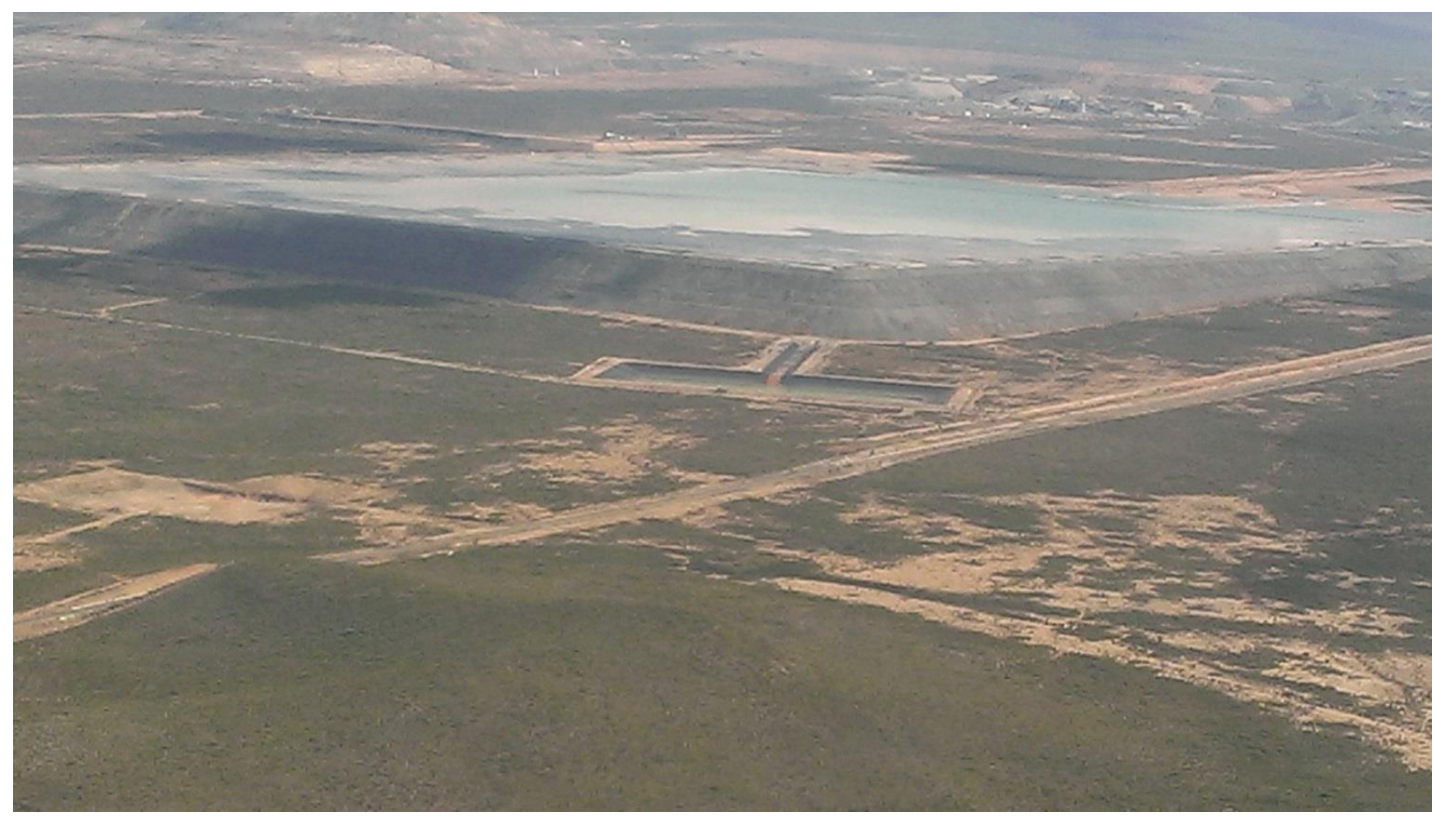

Figure 8 Tailings dam at Minera Penasquito

\section{Summary}

The implementation-based design concept has been developed over many projects, and it is primarily based on the responsible engineer's understanding of the goals of the project, and the main requirements governing the way to reach the expectations of the project, which is owner satisfaction, regulatory satisfaction, public satisfaction and environmental compliance.

\section{Acknowledgement}

I appreciate the support from Messrs Philip Spadaro (The Intelligence Group, USA), my father the late Arpad Fabian (Architect Engineering Tervezo Vallalat, Hungary) and the late Tom Scanland (Dames \& Moore, Australia) who were instrumental in my engineering development. The guidance from Professor Andy Fourie (Australian Centre for Geomechanics, Australia), my doctorate supervisor, was exceptional and greatly appreciated.

Furthermore, hundreds of younger and older colleagues gave me lots of advice and support over the years. I am grateful for their help.

\section{References}

Fabian, K, Jacobs, M, Hooshiar, A \& Ngwenya, E 2015, 'The impacts of using thickened tailings on water management and CAPEX of tailings storage facilities', in RJ Jewell \& AB Fourie (eds), Proceedings of the 18th International Seminar on Paste and Thickened Tailings, Australian Centre for Geomechanics, Perth, pp. 535-546.

Fabian, K, Schifano, V \& DeJong, J 2010, 'Design and pilot tests of binder stabilization of oily refinery and dredged marine sediments', in DO Fratta, AJ Puppala and B Muhunthan (eds), Proceedings of GeoFlorida 2010: Advances in Analysis, Modeling \& Design, American Society of Civil Engineers, Reston, pp. 2472-2481.

Fabian, K, Schifano, V, McCabe, M, Fellows, G \& Zigarlick, W 2002, 'The design of a double-lined tailings impoundment using upstream construction', Proceedings of the Association of State Dam Safety Officials Annual Conference 2002 (Tailing Dams), Association of State Dam Safety Officials, Lexington, pp. 1-12.

Kilkenny, R, Forbort, J, Fabian, K, Bush, D \& Steckelberg, A 2011, 'Dredging applied water treatment at a former nickel/copper mine', in R Randall (ed.), Proceedings of the 31st Western Dredging Association (WEDA XXXI) Technical Conference and the 42nd Texas A\&M (TAMU 42) Dredging Seminar, Western Dredging Association, Vancouver, pp. 185-195.

Schifano, V \& Fabian, K 2010, 'A laboratory study of binder stabilization of oily refinery and dredged marine sediments', Proceedings of GeoFlorida 2010: Advances in Analysis, Modeling \& Design, American Society of Civil Engineers, Reston, pp. 2482-2491.

Schifano, V, Fabian, K and Weise, T 2010, 'Stabilization of oily sediments for cap closure of a refinery oxidation pond', in CB Lake \& CD Hills (eds), Proceedings of the International Solidification/Stabilization Technology Forum, Dalhousie University Press, Halifax, pp. 11-20. 